\title{
Metabotropic Glutamate 2/3 Receptors in the Ventral Tegmental Area and the Nucleus Accumbens Shell Are Involved in Behaviors Relating to Nicotine Dependence
}

\author{
Matthias E. Liechti, ${ }^{1}$ Loic Lhuillier, ${ }^{2}$ Klemens Kaupmann, ${ }^{2}$ and Athina Markou ${ }^{1}$ \\ ${ }^{1}$ Department of Psychiatry, School of Medicine, University of California, San Diego, La Jolla, California 92093, and ${ }^{2}$ Neuroscience Research, Novartis \\ Institutes for Biomedical Research, Novartis Pharma, CH-4002 Basel, Switzerland
}

\begin{abstract}
The motivation to maintain nicotine self-administration and dependence may involve alterations in glutamatergic neurotransmission. Metabotropic glutamate (mGlu) 2/3 receptors regulate glutamate and dopamine release in the ventral tegmental area (VTA) and the nucleus accumbens (NAc) shell, two brain areas critically involved in reward and motivational processes. We found that acute systemic, as well as intra-VTA or intra-NAc, administration of the mGlu2/3 receptor agonist LY379268 [(-)-2-oxa-4-aminobicyclo[3.1.0]hexane4,6-dicarboxylate] decreased nicotine, but not food, self-administration in rats. In addition, nicotine self-administration downregulated mGlu2/3 receptor function in corticolimbic rat brain sites including the VTA and the NAc, demonstrated by decreased coupling of mGlu2/3 receptors to G-proteins in the $\left[{ }^{35} S\right] \mathrm{GTP} \gamma S$ binding assay. Furthermore, repeated treatment with LY379268 reduced nicotine self-administration at the beginning of a $14 \mathrm{~d}$ treatment period; however, the number of nicotine infusions earned gradually returned to baseline levels, indicating tolerance to the effects of repeated LY379268 treatment. Finally, LY379268 administration decreased both cue-induced reinstatement of nicotine- and food-seeking behavior. Together, these findings indicate an important role for mGlu2/3 receptors in the posterior VTA and the NAc shell in the mediation of the rewarding effects of nicotine and potentially in cue-induced nicotine-seeking behavior.
\end{abstract}

Key words: reward; nicotine; glutamate; self-administration; reinstatement; mGlu receptors

\section{Introduction}

Alterations in glutamatergic neurotransmission that may occur in response to chronic nicotine exposure may be critically involved in nicotine dependence by contributing to the motivation to maintain nicotine intake and the reinitiation of intake after a period of abstinence. Nicotine exerts its primary rewarding effects partly by activation of excitatory nicotinic acetylcholine receptors on glutamate terminals in the ventral tegmental area (VTA) that provide excitatory input to mesolimbic dopamine neurons projecting to the nucleus accumbens (NAc) shell (Kalivas, 1993; Mansvelder and McGehee, 2000; Schilstrom et al., 2000; Picciotto and Corrigall, 2002). The posterior VTA and the NAc shell are critically involved in reward and motivational processes related to drug dependence and abuse (Carlezon and Wise, 1996; Rodd-Henricks et al., 2000; Zangen et al., 2002). Nicotine is self-administered in the posterior, but not the anterior, VTA (Ikemoto et al., 2006). Furthermore, nicotine self-administration

Received April 18, 2007; revised July 7, 2007; accepted July 8, 2007.

This work was supported by National Institute on Drug Abuse Grant DA11946 (A.M.). M.E.L was supported by fellowship awards from the Swiss National Science Foundation (SNF-PBZHB-108501, SSMBS 1246, and F. Hofmann-La Roche, Basel, Switzerland). We thank Dr. Andre Der-Avakian, Dr. Neil E. Paterson, and Dr. Ronald Kuczenski for comments on this manuscript, Jessica Benedict and Jakob Heid for technical assistance, and Mike Arends for editorial assistance.

Correspondence should be addressed to Dr. Athina Markou, Department of Psychiatry, 0603, School of Medicine, University of California, San Diego, 9500 Gilman Drive, La Jolla, CA 92093-0603. E-mail: amarkou@ucsd.edu.

D0I:10.1523/JNEUROSCI.1766-07.2007

Copyright $\odot 2007$ Society for Neuroscience $\quad$ 0270-6474/07/279077-09\$15.00/0 preferentially increased dopamine output in the NAc shell compared with the NAc core (Lecca et al., 2006). Presynaptic metabotropic glutamate $2 / 3$ (mGlu2/3) autoreceptors, which negatively modulate excitatory glutamate transmission (Schoepp et al., 1999), are expressed in corticolimbic brain areas involved in reward processes, including the VTA and the NAc (Ohishi et al., 1993a,b; Tamaru et al., 2001; Richards et al., 2005). Accordingly, stimulation of $\mathrm{mGlu} 2 / 3$ receptors decreased extracellular glutamate in the NAc (Xi et al., 2002a) and dopamine in the NAc shell but not in the core (Greenslade and Mitchell, 2004). In contrast, mGlu2/3 receptor blockade increased dopamine in the NAc shell (Karasawa et al., 2006).

Drug-paired cues elicited an increase in glutamate within the NAc (Hotsenpiller et al., 2001). Similar increases in NAc glutamate were associated with drug-induced reinstatement of drugseeking behavior (Cornish and Kalivas, 2000; McFarland et al., 2003). Furthermore, microinjection of the $\mathrm{mGlu} 2 / 3$ receptor agonist LY379268 [(-)-2-oxa-4-aminobicyclo[3.1.0]hexane-4,6dicarboxylate] into the VTA or NAc shell, but not the core, attenuated context-induced reinstatement of heroin-seeking in rats (Bossert et al., 2004, 2006a).

Based on the above neurochemical and behavioral data, we hypothesized that decreasing glutamate neurotransmission by acute systemic administration of the mGlu2/3 receptor agonist LY379268 would reduce nicotine self-administration and cueinduced reinstatement of nicotine seeking, by antagonizing the 
nicotine- and cue-induced increases in glutamate transmission, respectively. Furthermore, we hypothesized that LY379268 would decrease nicotine self-administration when administered into the posterior VTA or the NAc shell. We also assessed the effects of repeated LY379268 administration on nicotine selfadministration, because medications for smoking cessation in humans need to be given chronically. Parallel studies were conducted with food pellets as the reinforcer to assess the selectivity of the effects of LY379268 on nicotine- versus food-maintained behavior. Finally, we examined whether repeated self-administration of nicotine would affect the function of $\mathrm{mGlu} 2 / 3$ receptors, as measured by the coupling of $\mathrm{mGlu} 2 / 3$ receptors to G-proteins, in corticolimbic brain areas known to be involved in the reinforcing effects of nicotine and other drugs of abuse.

\section{Materials and Methods \\ Animals}

Male Wistar rats (Charles River, Raleigh, NC) weighing 250-350 g were housed two per cage on a reversed $12 \mathrm{~h}$ light/dark cycle. All behavioral testing took place during the dark phase of the light/dark cycle. Rats had ad libitum access to water and were moderately food restricted to $20 \mathrm{~g}$ rat chow per day (Cabeza de Vaca and Carr, 1998; Campbell and Carroll, 2001). All procedures were conducted in accordance with the guidelines from the National Institutes of Health and the Association for the Assessment and Accreditation of Laboratory Animal Care.

\section{Testing chambers}

Intravenous nicotine self-administration and food-maintained responding took place in standard operant testing chambers $(24 \times 30 \times 28 \mathrm{~cm}$; Med Associates, St. Albans, VT) each housed in a sound-attenuated box. In each chamber, one wall contained two metal retractable levers (each $3 \times 1.8 \mathrm{~cm}$; active and inactive) mounted $6.5 \mathrm{~cm}$ above the metal grid floor of the chamber. Intravenous infusions were delivered by an infusion pump (Razel Scientific Instruments, Stamford, CT) through Tygon tubing protected by a spring lead that was connected on one end to a swivel to allow free movement of the animal and on the other end to the catheter base mounted in the midscapular region of the animal.

\section{Food training and food-maintained responding}

One week after arrival in the laboratory and before intravenous catheterization surgery (for the subjects that later self-administered nicotine), animals were trained to lever press for food (45 mg Noyes food pellets). Training started on a fixed-ratio 1 timeout $1 \mathrm{~s}$ (FR1 TO1 s) schedule of reinforcement. Only the active lever was used during food training. The schedule was then gradually increased over $4 \mathrm{~d}$ from FR1 TO1 s to FR1 TO10 s, FR2 TO20 s, and FR5 TO20 s, with sessions lasting $30 \mathrm{~min}$. Animals moved through the sequence only after successful acquisition of the previous schedule (defined as earning 50 pellets during a session). The training period lasted $\sim 5 \mathrm{~d}$. An identical training procedure was used for both the food-maintained responding subjects and the subjects that later were allowed to self-administer nicotine. After this initial training, food-responding subjects were allowed to respond for food on an FR5 TO20 s schedule, during which two levers (active and inactive) were present in the box.

\section{Nicotine self-administration training}

After successful acquisition of responding for food, animals were surgically prepared with intravenous catheters under isoflurane anesthesia as reported previously (Liechti and Markou, 2007). After recovery from intravenous catheter implantation, rats were allowed to self-administer nicotine $(0.03 \mathrm{mg} / \mathrm{kg}$ base/infusion) by switching the delivery of a food pellet for the delivery of a nicotine infusion. The lever previously paired with food delivery was paired with the delivery of nicotine infusion (active lever). It has been shown that, by using this procedure, nicotine self-administration and cue-induced reinstatement of nicotine-seeking behavior do not result from a lever bias attributable to previous experience with food reinforcement (Corrigall and Coen, 1989; Caggiula et al., 2002; Liu et al., 2006). Responses on the other lever (inactive lever) were recorded but had no consequences. Responding on the active lever re- sulted in the delivery of the nicotine solution in a volume of $0.1 \mathrm{ml}$ over a $1 \mathrm{~s}$ period. The delivery of an infusion was paired with a cue light located above the active lever, which was lit simultaneously with the initiation of the nicotine infusion and remained illuminated throughout the $20 \mathrm{~s}$ timeout period, during which responding was recorded but not reinforced. The delivery of an infusion was earned by responding five times on the active lever (FR5 TO20 s). Rats were considered to have acquired stable nicotine self-administration when they pressed the active lever more than twice the number of times they pressed the inactive lever and received a minimum of six infusions $/ 1 \mathrm{~h}$ session, with $<20 \%$ variance in the number of infusions earned per session over three consecutive sessions. Animals were allowed to self-administer nicotine $5 \mathrm{~d} /$ week. Completion of training to respond for food required $4-5 \mathrm{~d}$. Animals were then tested in the nicotine self-administration procedure for 3-5 weeks under baseline conditions to establish stable nicotine self-administration before the initiation of the assessment of the effects of the drug manipulations.

\section{Intracranial surgery and cannula placement verification}

Rats were anesthetized with isoflurane (1-3\%) in oxygen, and guide cannulas (26 gauge; Plastics One, Roanoke, VA) were implanted bilaterally $2.5 \mathrm{~mm}$ above the VTA or the NAc shell. The coordinates for the VTA were as follows: anteroposterior (AP), -6.0 from bregma; mediolateral (ML), \pm 0.6 ; and dorsoventral (DV), -5.3 from dura. The coordinates for the NAc shell were as follows: AP, +1.7 from bregma; $\mathrm{ML}, \pm 0.6$; and DV,$-4.5 \mathrm{~mm}$ from dura (Paxinos and Watson, 1998). At the end of the experiments, rats were anesthetized with pentobarbital and infused with $0.5 \mu \mathrm{l}$ of Evans blue. Rats were then decapitated, and the brains were removed and fixed in 10\% formalin. Coronal sections were sliced on a cryostat and stained with violet to verify the infusion sites. Only animals with accurate cannulas placement were included in the analysis (see Fig. 1).

\section{Drugs}

(-)Nicotine hydrogen tartrate was purchased from Sigma (St. Louis, $\mathrm{MO})$, dissolved in saline, and $\mathrm{pH}$ adjusted to $7.4( \pm 0.5)$ with sodium hydroxide. Nicotine doses are reported as base concentrations. LY379268 was custom synthesized according to the synthesis described previously (Monn et al., 1999) and purchased from ANAWA (Wangen, Switzerland). LY379268 was dissolved in sterile water, $\mathrm{pH}$ adjusted to 7.4 with sodium hydroxide, and administered either subcutaneously or intracranially $30 \mathrm{~min}$ before testing, consistent with previous work with this compound (Baptista et al., 2004; Bossert et al., 2004). LY379268 doses are reported as the salt.

\section{Experimental designs}

Experiment 1: effects of LY379268 on nicotine self-administration and foodmaintained responding. After stable self-administration was established ( $\pm 20 \%$ over three consecutive sessions), LY379268 was administered to three groups of naive rats either systemically $(n=7)$ or directly into the VTA $(n=9)$ or the NAc shell $(n=9)$ according to within-subjects Latin square designs. Systemic doses of LY379268 were $0,0.3,1$, and $3 \mathrm{mg} / \mathrm{kg}$, and intracranial doses were $0,0.3,0.6$, and $1 \mu \mathrm{g}$. LY379268 was administered $30 \mathrm{~min}$ before testing and only after animals had demonstrated stable self-administration behavior between drug/vehicle administrations, with at least $6 \mathrm{~d}$ between injection days.

To assess possible nonspecific actions of the $\mathrm{mGlu} 2 / 3$ receptor agonist, the effects of LY379268 $(0,0.3,1$, and $3 \mathrm{mg} / \mathrm{kg})$ were also assessed in animals trained to lever press for food on an FR5 TO20 $(n=8)$ or FR5 TO210 s $(n=8)$ schedule during $1 \mathrm{~h}$ sessions. The FR5 TO20 s schedule of reinforcement was identical in all parameters to the schedule under which nicotine was self-administered. The FR5 TO210 s schedule equated overall rates of responses emitted during the entire session for nicotine and food by using a longer timeout period. The effects of intraVTA $(n=9)$ or intra-NAc shell $(n=9)$ administration of LY379268 ( 0 , $0.3,0.6$, and $1 \mu \mathrm{g}$ ) on responding for food were assessed using the FR5 TO20 s schedule. Intracranial infusions were made using 33 gauge injectors (Plastics One) extending $2.5 \mathrm{~mm}$ below the tip of the guide cannula. A volume of $0.5 \mu \mathrm{l} /$ side was infused over $1 \mathrm{~min}$, and the injectors were left in place for $1 \mathrm{~min}$.

Experiment 2: effects of repeated administration of LY379268 on nicotine 
self-administration and food-reinforced responding. A between-subjects factorial design with four treatment groups was used for this experiment. Naive rats were used. After stable nicotine $(n=24)$ or food $(n=16)$ self-administration on an FR5 TO20 s schedule was established, animals received daily injections of LY379268 $(1 \mathrm{mg} / \mathrm{kg})(n=12$ for nicotineadministering and $n=8$ for food-administering rats) or vehicle ( $n=12$ for nicotine-administering and $n=8$ for food-administering rats) for 14 consecutive days $30 \mathrm{~min}$ before the test sessions. After the $14 \mathrm{~d}$ treatment, animals continued to self-administer nicotine/food for 3 more days. Brains were then removed for the assessment of $m G l u 2 / 3$ receptor function in the $\left[{ }^{35} \mathrm{~S}\right] \mathrm{GTP} \gamma \mathrm{S}$ binding assay.

Brain membrane preparation and $\left[{ }^{35} S\right]$ GTP $\gamma S$ binding assay. At the end of the above experiment, non-anesthetized animals $(n=12$, nicotine and LY379268 treatment; $n=12$, nicotine and vehicle treatment; $n=8$, food and LY379268 treatment; $n=8$, food and vehicle treatment) were decapitated $24 \mathrm{~h}$ after the last nicotine or food self-administration session (i.e., $72 \mathrm{~h}$ after the last LY379268 or vehicle injection). Brains were rapidly removed and dissected into coronal sections using a rat brain matrix. The brain regions were identified according to the rat brain atlas (Paxinos and Watson, 1998) and dissected on an ice-cooled metal plate using a round tissue punch $(1.5 \mathrm{~mm}$ in diameter). The bilateral brain sites dissected were the infralimbic cortex as part of the prefrontal cortex (PFC), the VTA, the NAc, the amygdala (AMY), the hypothalamus (HYP), and the hippocampus (HIPP). Brain punches were promptly transferred to tubes that were immediately frozen in cooled isopentane and subsequently placed on dry ice before being stored at $-80^{\circ} \mathrm{C}$. Tissues were homogenized in HEPES buffer, pH 7.7 (in mM: 20 HEPES, 10 $\mathrm{MgCl}_{2}, 2$ EGTA, and $100 \mathrm{NaCl}$ ) using a glass-glass homogenizer and centrifuged for $30 \mathrm{~min}$ at $4^{\circ} \mathrm{C}$ at $20,000 \times \mathrm{g}$. After resuspension in buffer, the pellet was rehomogenized and centrifuged again three times. The membranes were resuspended in $\left[{ }^{35} \mathrm{~S}\right] \mathrm{GTP} \gamma \mathrm{S}$ assay buffer [HEPES buffer as described above containing $30 \mu \mathrm{M}$ guanosine $5^{\prime}$-diphosphate (Sigma) and $\left.0.3 \mathrm{~nm}\left[{ }^{35} \mathrm{~S}\right] \mathrm{GTP} \gamma \mathrm{S}\right]$. Protein concentrations were determined using a BCA protein assay kit (Novagen, Madison, WI), and $10 \mu \mathrm{g}$ of protein was used per data point (96-well Packard Pico plates, $300 \mu \mathrm{l}$ volume). The reagents were incubated for $45 \mathrm{~min}$ at room temperature and subsequently filtered (Packard unifilter-GF/C). After two washes with the assay buffer described above, the plates were dried for $1 \mathrm{~h}$ at $50^{\circ} \mathrm{C}$ and then $50 \mu \mathrm{l}$ of scintillation solution (Microscint; PerkinElmer, Wellesley, MA) was added and the radioactivity counted. Basal levels were determined in the absence of test compounds.

Experiment 3: effects of LY379268 on cue-induced reinstatement of nicotine- or food-seeking behavior. Naive rats were trained to selfadminister nicotine $(n=32)$ or food $(n=40)$. After completion of self-administration training for $20 \mathrm{~d}$, rats were tested under extinction conditions (withholding of nicotine/food and its associated cue light) during 10 consecutive daily extinction sessions. Responses at both the inactive and active lever were recorded but had no consequences (i.e., no cue-light illumination, no infusion, and no syringe pump activation and noise). Also, during extinction sessions, rats were not attached to the tubing or the metal leads while in the operant chamber. The reinstatement test phase started $1 \mathrm{~d}$ after the last extinction session. During the reinstatement test sessions, responses at the active lever resulted in contingent presentation of the previously nicotine-associated cue light and the delivery of a saline infusion instead of nicotine in the nicotine group under an FR5 TO20 s schedule of reinforcement. For the nicotine group, four reinstatement sessions were conducted every fourth day (days 1, 5, 9, and 13 of the reinstatement phase) that were separated by three extinction sessions (cue and nicotine absent) to re-extinguish responding. Four doses of LY379268 $(0,0.3,1$, and $3 \mathrm{mg} / \mathrm{kg})$ were injected $30 \mathrm{~min}$ before each reinstatement test session according to a within-subjects Latin square design. A large number of animals $(n=32)$ was used for this experiment to allow for between-group comparisons of the effects of LY379268 ( $n=8$ per dose) on responding during the first of the four reinstatement sessions and allow the examination of whether a withinsubjects design with cue-induced reinstatement was feasible. For the food group, a between-subjects design was used because cue-induced foodseeking behavior exhibits rapid extinction with repeated reinstatement testing (Bespalov et al., 2005), prohibiting the use of a within-subjects design. Thus, four independent groups of rats $(n=10$ per group) responding for food were tested with different doses of LY379268 $(0,0.3,1$, and $3 \mathrm{mg} / \mathrm{kg}$ ) in a single reinstatement test session after an extinction phase of $10 \mathrm{~d}$. Similar designs have been used previously to test the effects of pharmacological treatments on cue-induced nicotine-seeking behavior in rats (Bespalov et al., 2005; Paterson et al., 2005; Liu et al., 2007). Cue-induced responding included the total number of responses emitted on the active lever, including the responses emitted during the $20 \mathrm{~s}$ timeout period when the cue light was illuminated. The cue condition used in the present study (20 s turn-on of cue light above the lever) was the same as used previously in our laboratory (Paterson et al., 2005) but differed from the cue conditions ( $1 \mathrm{~s}$ turn-on of light above the lever followed by $20 \mathrm{~s}$ turn-off of house light) used by the studies of Bespalov et al. (2005) and Liu et al. (2006). The cue light used in the Bespalov et al. and Liu et al. studies has primary reinforcing properties of its own that result in higher "reinstatement" rates reflecting both the primary reinforcing properties of the turning off of the house light as well as the acquired secondary reinforcing properties of the cue compound stimulus attributable to its previous predictive association with nicotine administration.

\section{Statistical analyses}

Acute effects of LY379268 on nicotine self-administration and foodmaintained responding were analyzed separately for each reinforcer and each route of drug administration using repeated-measures ANOVAs with LY379268 dose as the within-subjects factor. The effects of repeated injections of LY379268 on the number of nicotine or food rewards earned were assessed using two-way ANOVAs with dose as the betweensubjects factor and time as the within-subjects factor. The effects of LY379268 in the anatomical control sites were compared with the effects of the same LY379268 doses into the intended brain sites using paired $t$ tests. The effects of nicotine and LY379268 administration on LY354740induced stimulation of GTP $\gamma^{35} \mathrm{~S}$ binding were assessed by three-way ANOVA with LY354740 dose as the within-measurement factor and reward (nicotine vs food) and LY379268 dose (0 vs $1 \mathrm{mg} / \mathrm{kg}$ ) as betweengroup factors. ANOVAs with dose as the within-subjects factor (for nicotine-seeking data) or between-subjects factor (for food-seeking data) were used to analyze the effects of LY379268 on cue-induced reinstatement of nicotine- and food-seeking behavior. Because Kolmogorov-Smirnov tests indicated significant deviance from normality, the reinstatement data were log-transformed before performing the ANOVAs to fit a normal distribution. Post hoc comparisons were made with Newman-Keuls tests. A $p$ value of $<0.05$ was considered significant. Prism 4.0 (GraphPad, San Diego, CA) and STATISTICA 6 (StatSoft, Tulsa, OK) software were used for data analyses.

\section{Results}

Experiment 1: effects of systemic, intra-VTA, and intra-NAc shell administration of LY379268 on nicotine selfadministration and food-reinforced responding

Figure 1 shows the histologically confirmed microinjection sites in the VTA and the NAc shell. Systemic LY379268 administration significantly and dose-dependently decreased nicotine selfadministration (one-way ANOVA, main effect of dose, $F_{(3,18)}=$ 38.47, $p<0.001$ ) (Fig. $2 A$ ), whereas it had no effect on inactive lever presses at any of the doses tested. Mean \pm SEM responding on the inactive lever was $1 \pm 0.7,1.6 \pm 0.7,0.2 \pm 0.2$, and $0.7 \pm$ 0.5 after $0,0.3,1$, and $3 \mathrm{mg} / \mathrm{kg}$ LY379268, respectively. LY379268 microinjection into either the VTA or the NAc shell also significantly reduced nicotine self-administration $\left(F_{(3,24)}=7.46, p<\right.$ 0.001 and $F_{(3,24)}=3.92, p<0.03$, respectively) (Fig. $2 B, C$ ). Mean \pm SEM responding on the inactive lever was $6.9 \pm 2.5$, $6.4 \pm 3.5,2.8 \pm 1$, and $0.3 \pm 0.3$ after intra-VTA and $7.1 \pm 2$, $6.1 \pm 2.3,6.1 \pm 2.9$, and $5.8 \pm 3.2$ after intra-NAc shell administration of $0,0.3,0.6$, and $1 \mu \mathrm{g}$ LY379268, respectively. There were no statistically significant differences. Anatomical control injections outside the target brain sites were made using the lowest LY379268 dose that had a significant effect when injected into 
the target site. Injection of LY379268 $2 \mathrm{~mm}$ above the NAc shell into the lateral septal nucleus ( $1 \mu \mathrm{g}$ of LY379268, in animals previously injected with the compound into the NAc shell) or $2 \mathrm{~mm}$ above the VTA into the red nucleus $(0.6 \mu \mathrm{g}$ of LY379268, in animals previously injected with the compound into the VTA) had no effect on nicotine self-administration (Fig. $2 B, C$, respectively). Nicotine self-administration was decreased after the injection of $0.6 \mu \mathrm{g}$ of LY379268 into the NAc shell or $1 \mu \mathrm{g}$ of LY379268 into the VTA compared with the corresponding anatomical control injection ( $t$ tests, $F_{(1,8)}=19, p<0.01$ and $F_{(1,6)}=5.5, p=0.055$, respectively) (Fig. $2 B, C)$.

LY379268 decreased the number of food rewards earned under both the FR5 TO20 s schedule $\left(F_{(3,21)}=5.49, p<0.01\right)$ and the FR5 TO210 s schedule $\left(F_{(3,21)}=\right.$ $10.32, p<0.001$ ) but only at the $3 \mathrm{mg} / \mathrm{kg}$ dose at both schedules, whereas lower doses had no effect (Fig. $2 A, D$ ). Thus, the systemic dose of $1 \mathrm{mg} / \mathrm{kg}$ LY379268 selectively decreased nicotine, but not food, self-administration. LY379268 doses that reduced nicotine self-administration $(0.6$ and $1 \mu \mathrm{g}$ ) had no effect on foodmaintained responding when injected into the NAc shell or the VTA (Fig. 2E,F). There were no significant differences in the effects of LY379268 on nicotine- or food self-administration across test sessions $1-4$, i.e., no order effects. Systemic, intra-VTA, or intra-NAc shell administration of LY379268 had no effect on inactive lever pressing. On the FR5 TO20 schedule of reinforcement, mean \pm SEM responding on the inactive lever was $1 \pm 0.5,1.4 \pm$ $0.7,1.6 \pm 1$, and $3.1 \pm 1$ after $0,0.3,1$, and $3 \mathrm{mg} / \mathrm{kg}$ LY379268, respectively. More than half of the animals on the FR5 TO210 schedule of reinforcement did not respond on the inactive lever (similar median responding was 0 per session for all doses of LY379268 or vehicle). Mean \pm SEM responding on the inactive lever was $4.8 \pm$ $0.8,8.4 \pm 4.1,6 \pm 3.6$, and $2.8 \pm 1.6$ after intra-VTA and $4.7 \pm 2.1,8 \pm 3.5,9.6 \pm$ 2.5 , and $6.3 \pm 2.9$ after intra-NAc shell administration of $0,0.3,0.6$, and $1 \mu \mathrm{g}$ LY379268, respectively.

In the nicotine self-administering animals, mean \pm SEM body weights increased from $428 \pm 5$ to $448 \pm 7$ g during the treatment period. In the food selfadministering animals, mean \pm SEM body weights changed from $359 \pm 8$ to $410 \pm 5 \mathrm{~g}$ in the TO $20 \mathrm{~s}$ group and from $402 \pm 13$ to $393 \pm 13 \mathrm{~g}$ in the TO $210 \mathrm{~s}$ group. Thus, similar increases in body weights were observed in the nicotine self-administration group and the TO $20 \mathrm{~s}$ food group, whereas body weights did not increase in the TO

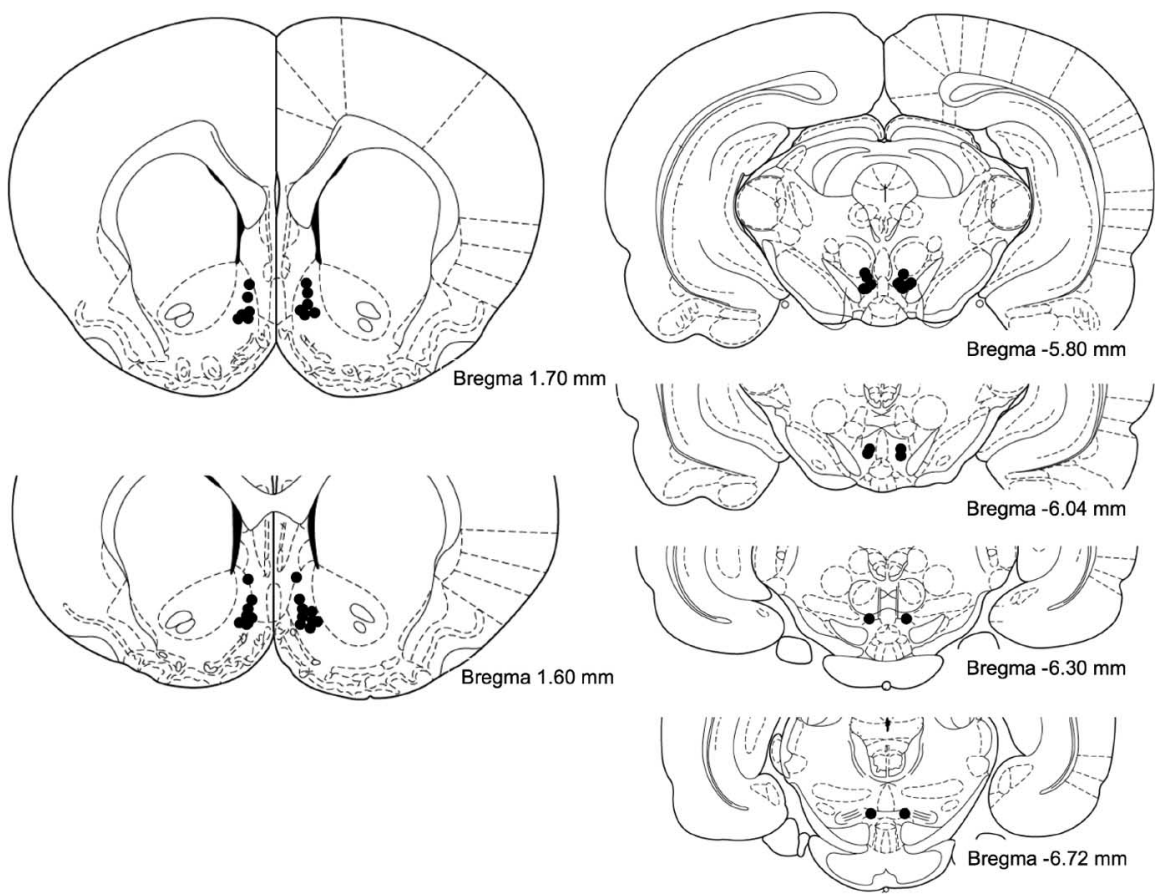

Figure 1. Diagrams of coronal sections from the rat brain (Paxinos and Watson, 1998). Black circles indicate histologically confirmed locations of injector tips inside the NAc shell (bregma $1.70-1.60 \mathrm{~mm}$ ) and the VTA (bregma -5.80 to $-6.72 \mathrm{~mm}$ ).
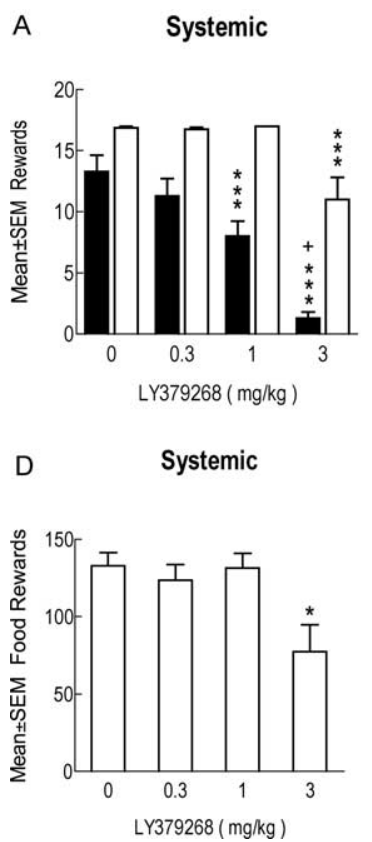
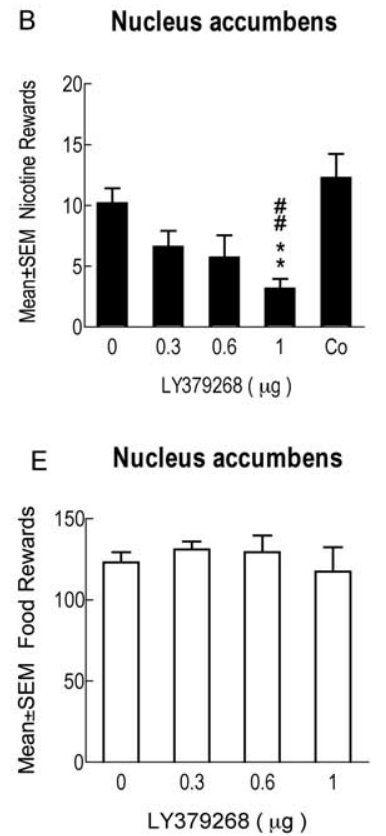

C Ventral tegmental area

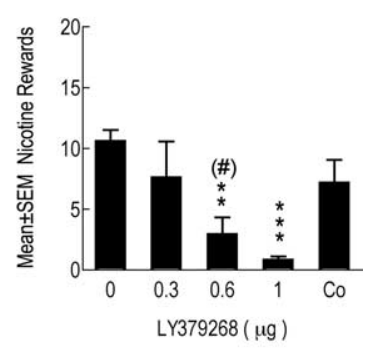

F Ventral tegmental area

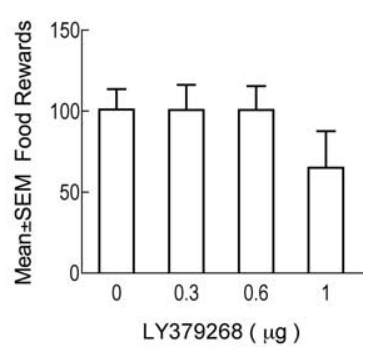

Figure 2. Systemic LY379268 injection decreased nicotine ( $A$, black bars; $n=7$, timeout $20 \mathrm{~s}$ ) but not food self-administration, except at the highest LY379268 dose ( $\boldsymbol{A}$, white bars; $n=8$, timeout 210 s). LY379268 injection into the NAc shell $(\boldsymbol{B} ; n=9)$ or the VTA $(\boldsymbol{C} ; n=9)$ decreased nicotine self-administration. Control injection of $1 \mu \mathrm{g}$ of $\mathrm{LY} 3792682 \mathrm{~mm}$ above the NAc shell into the lateral septal nucleus had no effect on nicotine self-administration ( $\boldsymbol{B} ; \boldsymbol{C}$, control injection; $n=9)$. Injection of $0.6 \mu \mathrm{g} 2 \mathrm{~mm}$ above the VTA into the red nucleus had no effect on nicotine self-administration $(\boldsymbol{C} ;(0$, control injection; $n=7)$. Number of food pellets earned after systemic LY379268 ( $\boldsymbol{D} ; n=8)$, intra-NAcshell $(\boldsymbol{E} ; n=9)$, or intra-VTA $(\boldsymbol{F} ; n=9)$ injection under the FR5 T020 sschedule of reinforcement. ${ }^{*} p<0.05,{ }^{* *} p<0.01,{ }^{* * *} p<0.001$, different from $0 \mathrm{mg} / \mathrm{kg} \mathrm{LY} 379268 ;{ }^{+} p<0.05$, different from $1 \mathrm{mg} / \mathrm{kg}$ LY379268. ${ }^{\#} p<0.06,{ }^{\# \#} p<0.001$, different from control injection.

$210 \mathrm{~s}$ group, presumably attributable to higher body weights at the start of the experiment and smaller food intake during the food administration sessions on the TO 210 s schedule. Importantly, LY379268 had an identical effect on food-maintained re- 


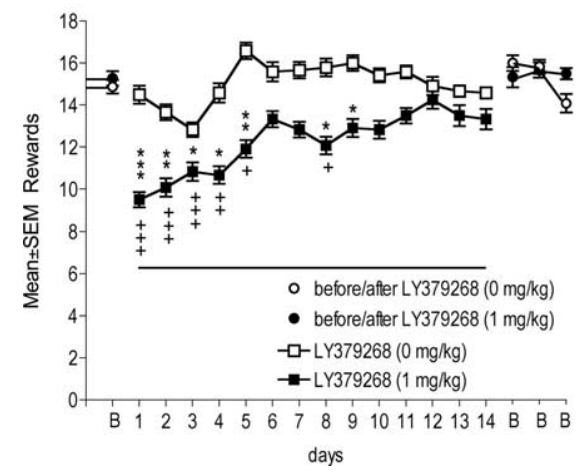

B

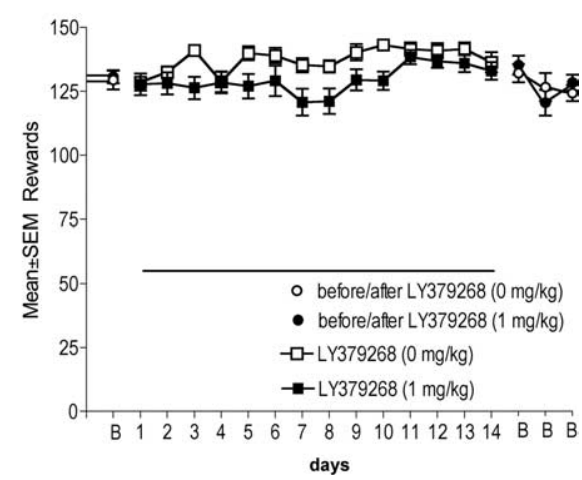

Figure 3. Effects of repeated LY379268 administration on nicotine and food self-administration. $A$, LY379268 $(1 \mathrm{mg} / \mathrm{kg})$ decreased nicotine self-administration $\left({ }^{*} p<0.05,{ }^{* *} p<0.01,{ }^{* * *} p<0.001\right.$, different from vehicle condition, LY379268 at 0 $\mathrm{mg} / \mathrm{kg} ;{ }^{+} p<0.05,{ }^{++} p<0.01,{ }^{+++} p<0.001$, different from baseline responding), but tolerance developed over the $14 \mathrm{~d}$ period ( $n=12$ per dose). $\boldsymbol{B}, \mathrm{L} \mathrm{L} 379268(1 \mathrm{mg} / \mathrm{kg}$ ) had no effect on food-maintained responding ( $n=8$ per dose). Line under data points (days 1-14) depicts the days when LY379268 administration occurred. B, Baseline responding (mean of preceding $3 \mathrm{~d}$ ) and responding on days after LY379268 administration.

sponding in the two food groups regardless of the differences in body weight changes. For the experiments that tested the effects of intra-VTA and intra-NAc LY379268 administration on nicotine and food self-administration, weight changes during the treatment period were as follows: mean \pm SEM body weight changed from $380 \pm 6$ to $393 \pm 7 \mathrm{~g}$, from $384 \pm 14$ to $412 \pm 15$, from $386 \pm 6$ to $405 \pm 6 \mathrm{~g}$, and from $378 \pm 11$ to $405 \pm 9 \mathrm{~g}$ in the NAc/nicotine group, the NAc/food group, the VTA/nicotine group, and the VTA/food group, respectively. There were no significant baseline or weight gain differences in body weights between these treatment groups.

Experiment 2: effects of repeated LY379268 administration on nicotine self-administration and food-reinforced responding A significant drug $\times$ time interaction $\left(F_{(17,374)}=2.20, p<0.01\right)$ revealed that LY379268 administration differentially decreased nicotine self-administration over time. Confirming the effects of acute administration of LY379268 (experiment 1), repeated daily LY379268 treatment significantly reduced nicotine infusions earned compared with infusions earned after vehicle administration for the first five treatment days (Fig. 3A). A steady increase in nicotine self-administration over time in LY379268-treated animals indicated the development of tolerance to the effect of repeated LY379268 treatment by day 10 of treatment.

In replication of the results reported in experiment 1 , food intake was not affected by daily treatment with $1 \mathrm{mg} / \mathrm{kg}$ LY379268, and responding remained stable over the $14 \mathrm{~d}$ treatment phase and after termination of LY379268 treatment (Fig. 3B).

During the $10 \mathrm{~d}$ treatment period, mean \pm SEM body weights increased from $344 \pm 1.6$ to $357 \pm 2.3 \mathrm{~g}$, from $346 \pm 2.0$ to $366 \pm$ $2.3 \mathrm{~g}$, from $379 \pm 5.6$ to $404 \pm 5.7 \mathrm{~g}$, and from $394 \pm 4$ to $426 \pm$ $4.5 \mathrm{~g}$ in the nicotine/LY379268 group, the nicotine/vehicle group, the food/LY379268 group, and the food/vehicle group, respectively. Body weights were higher in the food compared with the nicotine groups (main effect of reinforcer, $F_{(1,36)}=23, p<$ 0.001). Body weights increased more in the food compared with the nicotine groups, possibly attributable to additional food intake during the test sessions (reinforcer $\times$ time interaction, $\left.F_{(1,36)}=16, p<0.001\right)$. There were no differences in weight gains

between the LY379268 and the vehicle groups over the $10 \mathrm{~d}$ treatment period.

Experiment 2: effects of nicotine selfadministration and repeated LY379268 treatment on $\mathrm{mGlu} 2 / 3$ receptor agonistinduced $\left[{ }^{35} S\right]$ GTP $\gamma S$ binding

Stimulation of $\left[{ }^{35} \mathrm{~S}\right] \mathrm{GTP} \gamma \mathrm{S}$ binding by the mGlu2/3 receptor agonist LY354740 in PFC, NAc, VTA, AMY, HYP, and HIPP homogenates was significantly decreased in nicotine self-administering rats compared with food-administering rats (LY354740 $\times$ reward interactions, $F_{(5,100)}=14.20, p<$ $0.001 ; F_{(5,100)}=10.50, p<0.001 ; F_{(5,100)}=$ $2.67, p<0.03 ; F_{(5,100)}=48.54, p<0.001$; $F_{(5,100)}=7.19, p<0.001 ; F_{(5,100)}=5.88, p<$ 0.001 , respectively for each brain site) (Fig. 4). The nicotine effect was maximal in the PFC and AMY followed by the HIPP and NAc, but only moderate in the VTA and HYP. Similarly to nicotine selfadministration, repeated LY379268 administration decreased LY354740-induced $\left[{ }^{35} \mathrm{~S}\right] \mathrm{GTP} \gamma \mathrm{S}$ binding in the PFC $\left(F_{(5,100)}=21.33, p<0.001\right)$. In contrast, repeated LY379268 increased LY354740-induced $\left[{ }^{35} S\right]$ GTP $\gamma S$ binding in the $\operatorname{NAc}$ and $\operatorname{AMY}\left(F_{(5,100)}=2.88, p<0.05\right.$ and $F_{(5,100)}=5.56$, $p<0.001)$ and had no effect in the VTA, HYP, and HIPP. There were no interacting effects of nicotine and LY379268 on LY354740-induced $\left[{ }^{35} \mathrm{~S}\right] \mathrm{GTP} \gamma \mathrm{S}$ binding.

\section{Experiment 3: effects of LY379268 administration on cue-} induced reinstatement of nicotine- and food-seeking behavior During the last $3 \mathrm{~d}$ of nicotine self-administration, animals responded (mean \pm SEM) $87.5 \pm 6.1$ times at the active lever, resulting in $13.3 \pm 0.8$ nicotine infusions per daily $1 \mathrm{~h}$ session. During the first extinction session, the mean number of responses was 78.4 \pm 7.4 at the active lever, and responses gradually decreased to $16.8 \pm 2.1$ during the last 3 of the 10 extinction sessions, corresponding to $20.5 \pm 3.2 \%$ of the number of presses during nicotine self-administration. The total number of active lever presses significantly decreased during the nicotine- and cueabsent extinction sessions $\left(F_{(10,31)}=47.15, p<0.001\right)$. Responding was significantly decreased on days 2 through 10 of the extinction phase compared with the mean of the last $3 \mathrm{~d}$ of nicotine self-administration ( $p<0.001$ for all comparisons; data not shown graphically). LY379268 significantly reduced cue-induced reinstatement of nicotine-seeking behavior (main effect of dose, $\left.F_{(3,93)}=14.17, p<0.001\right)$ at the 1 and $3 \mathrm{mg} / \mathrm{kg}$ doses compared with nicotine seeking after vehicle treatment ( $p<0.001$ for both) (Fig. 5A). LY379268 also significantly reduced cue-induced reinstatement of nicotine seeking when only the data of the first reinstatement session were analyzed using an identical betweensubjects ANOVA design as that used to analyze the reinstatement of food-seeking data (Fig. 5, inset). There were no significant differences in the reinstatement response across reinstatement sessions 1-4, i.e., no order effect. In the vehicle pretreated animals, mean \pm SEM numbers of lever presses during reinstatement sessions $1-4$ were $46 \pm 8.5,30 \pm 4.4,26 \pm 2.6$, and $39 \pm$ 6.7 , respectively. Responding on the inactive lever was very low (median response of 0 or 1 per session for all experimental groups) and not significantly affected by LY379268 administration. Mean \pm SEM responding on the inactive lever was $1.7 \pm 0.6$ 
at the end of the extinction period and $0.5 \pm 0.3,0.4 \pm 0.3,0.3 \pm 0.2$, and $0.4 \pm$ 0.2 during reinstatement after $0,0.3,1$, and $3 \mathrm{mg} / \mathrm{kg}$ LY379268, respectively.

The number of active lever presses during the last three food training sessions was (mean \pm SEM) $1030 \pm 62.8$. The number of lever presses significantly decreased during the food- and cue-absent sessions $\left(F_{(10,320)}=186.02, p<0.001\right)$. When compared with the nicotine extinction sessions, food seeking decreased more rapidly and responding was already significantly decreased during the first extinction session compared with the last $3 \mathrm{~d}$ of food intake ( $p<0.001$ for all extinction sessions; data not shown graphically). This rapid extinction of food-seeking behavior necessitated the use of a between-subjects design for the assessment of the effects of LY379268 on cue-induced reinstatement of food seeking. The number of active responses during the last $3 \mathrm{~d}$ of extinction was $30.9 \pm 3.3$ or $3.5 \pm 0.5 \%$ of the number of lever presses during foodmaintained responding. Although absolute response rates were higher, percentage of responses were lower compared with the nicotine group. Reinstatement of food-seeking behavior was significantly decreased by LY379268 pretreatment (main effect of dose, $F_{(3,36)}=5.54, p<$ 0.01 ) (Fig. 5B). The effect of LY379268 was not dose dependent and was seen after administration of all doses of LY379268. This decrease was statistically significant for the 3 mg/kg LY379268 dose. Responding on the inactive lever was low and not significantly affected by LY379268 administration. Mean \pm SEM responding on the inactive lever was $2 \pm 0.8$ at the end of the extinction period and $2.3 \pm 1,1.4 \pm 0.6$, $0.8 \pm 0.4$, and $0.4 \pm 0.3$ after $0,0.3,1$, and $3 \mathrm{mg} / \mathrm{kg} \quad$ LY379268 administration. Mean \pm SEM body weights at the time of reinstatement of nicotine or food seeking were $418 \pm 5.3 \mathrm{~g}$ in the nicotine group and $395 \pm 4.1 \mathrm{~g}$ in the food group.

\section{Discussion}

Administration of the $\mathrm{mGlu} 2 / 3$ receptor agonist LY379268 systemically or directly into the posterior VTA or the NAc shell dose dependently decreased nicotine selfadministration at doses that had no effect on responding for food. Daily nicotine self-administration resulted in downregulation of $\mathrm{mGlu} 2 / 3 \mathrm{re}$ ceptor function, as assessed by decreased coupling of mGlu2/3 receptors to G-proteins in the GTP $\gamma^{35} \mathrm{~S}$ binding assay in all cortical and limbic brain sites analyzed. Finally, acute systemic injections of LY379268 reversed cue-induced reinstatement of both nicotine- and food-seeking behavior. Together, these results suggest a critical role for $\mathrm{mGlu} 2 / 3$ receptors, particularly in the VTA cue presentation.
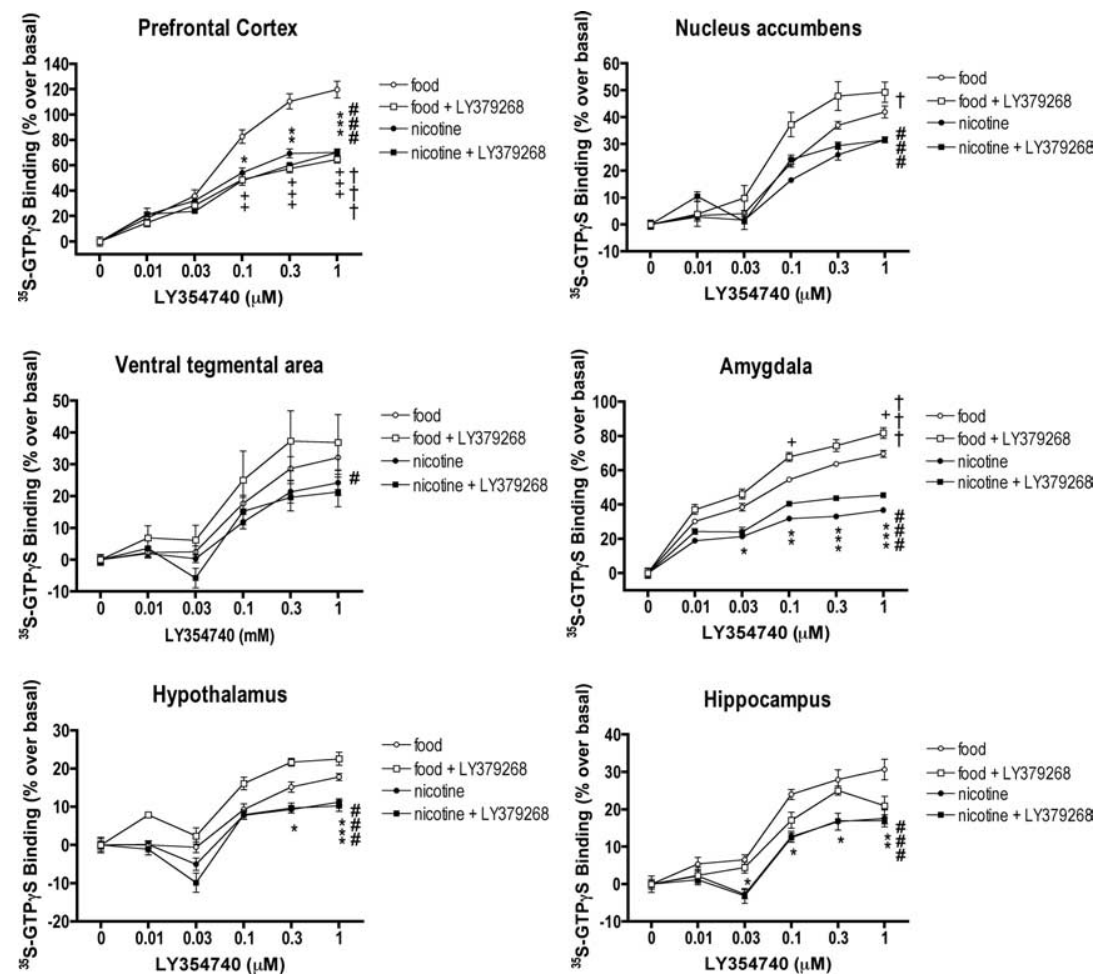

Figure 4. Effects of nicotine and LY379268 on functional coupling of mGlu2/3 receptors to G-proteins. Stimulation of $\left[{ }^{35} \mathrm{~S}\right] \mathrm{GTP} \gamma \mathrm{S}$ binding by the mGlu2/3 receptor agonist LY354740 was significantly decreased in rats self-administering nicotine compared with animals responding for food, suggesting mGlu2/3 receptor downregulation in all assessed brain areas (LY354740 × reward interactions; ${ }^{\#} p<0.05,{ }^{\# \#} p<0.001 ;{ }^{*} p<0.05,{ }^{* *} p<0.01,{ }^{* * *} p<0.001$, different from food). Repeated LY379268 administration also decreased [ ${ }^{35}$ S] GTP $\gamma$ S binding in the prefrontal cortex and increased $\left[{ }^{35} \mathrm{~S}\right] \mathrm{GTP} \gamma \mathrm{S}$ bind ing in the nucleus accumbens and amygdala (LY354740 X LY379268 interactions, ${ }^{\dagger} p<0.05,{ }^{+{ }^{+\dagger}} p<0.001{ }^{+}{ }^{+} p<0.05,{ }^{++} p<$ $0.01,{ }^{++} p<0.001$, different from food). Data represent mean $\pm \mathrm{SEM} ; n=6$.

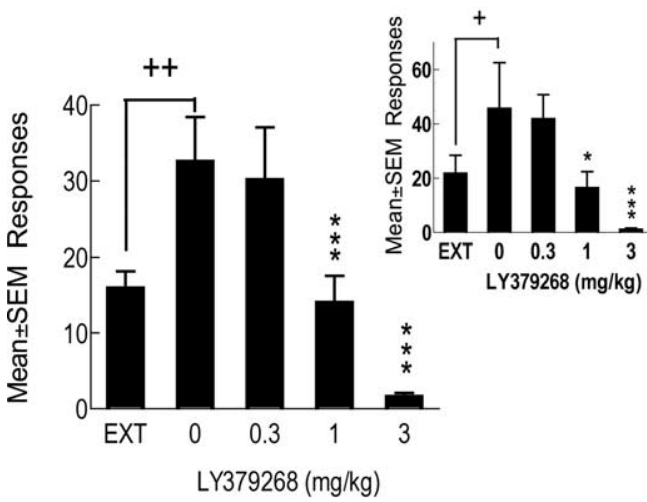

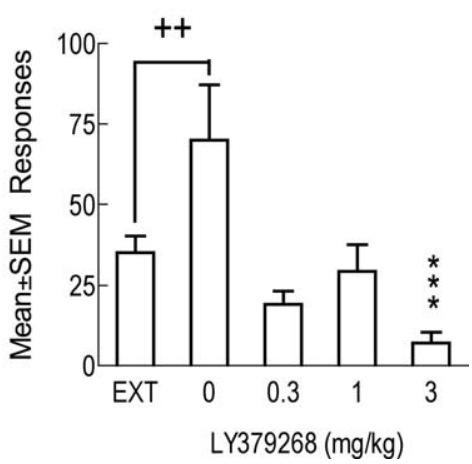

Figure 5. Effects of LY379268 on cue-induced reinstatement of nicotine and food seeking. LY379268 blocked reinstatement for both nicotine ( $\boldsymbol{A} ; n=32$; within-subject comparison) and food ( $\boldsymbol{B} ; n=10$ per dose; between-subject comparison) seeking. $\boldsymbol{A}$, Inset, Reinstatement for nicotine seeking for the first of the four reinstatement test sessions ( $n=8$ per dose; between-subjects comparison; for details, see Materials and Methods). ${ }^{+} p<0.05,{ }^{++} p<0.01$, different from extinction. ${ }^{*} p<0.5$, ${ }^{* * *} p<$ 0.001 , different from $0 \mathrm{mg} / \mathrm{kg}$ LY379268. EXT, Extinction; Responses, total of active lever presses including responses during the

and the NAc shell, in the primary rewarding effects of nicotine and the motivational impact of environmental stimuli previously associated with nicotine self-administration. The adaptations occurring in the function of $\mathrm{mGlu} 2 / 3$ receptors with chronic nicotine exposure are likely to contribute to maintenance of nicotine dependence and reinstatement of nicotine-seeking behavior.

Consistent with our results of the effects of the mGlu $2 / 3$ re- 
ceptor agonist LY379268 on nicotine self-administration, LY379268 decreased cocaine self-administration (Baptista et al., 2004, 2005; Adewale et al., 2006). In contrast, LY379268 did not decrease heroin (Bossert et al., 2005) or ethanol (Backstrom and Hyytia, 2005; Rodd et al., 2006) self-administration, except at doses that also decreased locomotor activity. Together, these results suggest that increased glutamate transmission selectively mediates the primary reinforcing effects of psychostimulants, including nicotine, but may be less involved in the reinforcing effects of sedatives, such as opiates or ethanol.

Repeated systemic administration of an LY379268 dose that reduced nicotine self-administration when given once led to tolerance, reflected in a gradual return of nicotine selfadministration to baseline levels. This tolerance may indicate pharmacokinetic autoinduction of LY379268 metabolism or that mGlu2/3 receptors undergo functional adaptations with chronic receptor agonist treatment. Although pharmacokinetic tolerance cannot be excluded, pharmacodynamic tolerance is demonstrated by our finding that mGlu $2 / 3$ receptor function was downregulated in animals repeatedly treated with LY379268 in the PFC and upregulated in the NAc and AMY. This observed tolerance to repeated LY379268 administration indicates that treatment with an $\mathrm{mGlu} 2 / 3$ receptor agonist in a clinical setting in humans may lose its efficacy over time.

The present study also demonstrated that the mGlu2/3 receptor agonist LY379268 decreased cue-induced reinstatement of nicotine-seeking behavior at doses similar to those that decreased reinstatement of food seeking. These results extend previous findings showing that LY379268 decreased reinstatement of drug seeking for cocaine (Baptista et al., 2004; Moran et al., 2005; Peters and Kalivas, 2006; Zhao et al., 2006), ethanol (Backstrom and Hyytia, 2005; Rodd et al., 2006), and heroin (Bossert et al., $2004,2005)$. However, LY379268 also reduced cue-induced reinstatement of food-seeking behavior in the present study, consistent with previous reports of LY379268 reducing food pellet (Peters and Kalivas, 2006), sweetened condensed milk (Baptista et al., 2004), and sucrose (Bossert et al., 2006b) seeking, without impairing locomotion (Cartmell et al., 1999, 2000; Bossert et al., 2006b). Together, these results indicate nonspecific effects of LY379268 on the motivational properties of conditioned reinforcers and suggest that the glutamatergic mechanisms underlying seeking of drugs of abuse overlap with those for seeking of natural rewards. Studies showed that intra-VTA and intra-NAc shell, but not intra-substantia nigra or intra-NAc core, microinjections of LY379268 attenuated contextual cue-induced reinstatement of heroin seeking in rats (Bossert et al., 2004, 2006a). In addition, LY379268 injection into the NAc core inhibited cueinduced reinstatement of cocaine and food seeking (Peters and Kalivas, 2006). Although there may be dissociations in some neural substrates mediating the primary rewarding effects of drugs of abuse and drug seeking (Kalivas and Volkow, 2005), the results demonstrate a role for $\mathrm{mGlu} 2 / 3$ receptors in the VTA and the NAc shell in the mediation of both the primary rewarding effects of drugs of abuse and the secondary reinforcing properties of stimuli previously associated with drugs of abuse. It is unlikely that the effects of the intra-VTA and intra-NAc injections of LY379268 on nicotine self-administration were caused by a locomotor deficit because there were no effects of similar intracranial injections of LY379268 on responding for food (present study) or sucrose [intra-VTA injections (Bossert et al., 2006a)] or locomotor activity [intra-NAc shell injections (Bossert et al., 2005)].

In support of a critical role of $\mathrm{mGlu} 2 / 3$ receptors in the development of nicotine dependence, nicotine self-administration downregulated $\mathrm{mGlu} 2 / 3$ receptor function, demonstrated by decreased coupling of $\mathrm{mGlu} 2 / 3$ receptors to G-proteins in the GTP $\gamma^{35}$ S binding assay in all brain sites assessed that included the PFC, NAc, VTA, AMY, HYP, and HIPP. Metabotropic glutamate $2 / 3$ receptors mainly function as inhibitory autoreceptors to control glutamate release (Conn and Pin, 1997; Hu et al., 1999; Cartmell and Schoepp, 2000; Xi et al., 2002a). Thus, a decrease in $\mathrm{mGlu} 2 / 3$ receptor function indicates impaired negative feedback control on glutamatergic terminals, possibly leading to a hyperglutamatergic response to nicotine within the corticolimbic system. In support of this interpretation, chronic nicotine selfadministration increased expression levels of postsynaptic ionotropic glutamate receptor subunits in the PFC and VTA (Wang et al., 2007), also indicating enhanced glutamatergic neurotransmission within the mesocorticolimbic pathway during nicotine self-administration. Similar enhancing effects on glutamate transmission were observed with repeated administration of other psychostimulant drugs. Specifically, repeated cocaine administration potentiated the glutamate release induced by a subsequent cocaine injection (Pierce et al., 1996; Bell et al., 2000). Furthermore, repeated exposure to amphetamine enhanced selfadministration and overflow of glutamate and dopamine in the NAc, an effect blocked by the mGlu2/3 receptor agonist LY379268 (Kim et al., 2005). Finally, similar to our results with nicotine, $\mathrm{Xi}$ et al. (2002b) found that daily experimenteradministered cocaine for 1 week reduced the efficiency of mGlu2/3 receptors in the NAc and PFC to couple to G-proteins in the GTP $\gamma^{35} \mathrm{~S}$ binding assay 3 weeks after cocaine exposure. Furthermore, 3 weeks after the cocaine treatment, there were decreased baseline extracellular glutamate levels in the NAc (Xi et al., 2002b; Baker et al., 2003; Moran et al., 2005). Finally, experimenter- or self-administered chronic nicotine led to adaptations in NMDA, AMPA/kainate, and $\mathrm{mGlu2} / 3$ receptor function (Kenny et al., 2003), effects consistent with decreased baseline glutamate transmission (Markou, 2007).

Repeated LY379268 administration downregulated mGlu2/3 receptor function in food self-administering animals in the PFC, similar to the effect of nicotine self-administration. This finding suggests that $\mathrm{mGlu} 2 / 3$ receptors exhibit plasticity and downregulation during repeated stimulation with either repeated nicotineinduced increases in glutamate release or repeated activation by an exogenous receptor agonist, such as LY379268. Thus, the observed tolerance to the effects of LY379268 on nicotine selfadministration may be attributable to downregulation of mGlu2/3 receptors in the PFC, implicating an important role of $\mathrm{PFC} \mathrm{mGlu} 2 / 3$ receptors in behaviors related to drug dependence (Xi et al., 2002b).

Together, these data indicate that psychostimulant-induced neuroadaptations in glutamate system function include a combination of reduced baseline glutamate levels coupled with decreased $\mathrm{mGlu} 2 / 3$ receptor function, with the latter contributing to loss of regulatory feedback control on synaptic glutamate release during activation induced by additional drug administration and/or exposure to environmental stimuli that lead to reinstatement of drug seeking (Kalivas, 2004).

Although our results are consistent with studies showing mGlu2/3 receptor downregulation after repeated cocaine administration in the PFC, NAc (Xi et al., 2002b), and AMY (Neugebauer et al., 2000), there are important differences. In the study by Xi et al. (2002b), cocaine was experimenter administered and not self-administered by the subjects as in our study. Furthermore, in the study by $\mathrm{Xi}$ et al., mGlu2/3 receptor function was assessed 3 weeks after $7 \mathrm{~d}$ of repeated cocaine injections. In con- 
trast, in the present study, nicotine-induced adaptations in mGlu2/3 receptor function in mesocorticolimbic brain areas were assessed $24 \mathrm{~h}$ after nicotine self-administration at a time when the next nicotine self-administration would have occurred. This time point is likely to be associated with anticipation of access to nicotine and thus probably reflects an activated "relapse” state. Accordingly, our findings of impaired mGlu2/3 receptor function reflect adaptations to repeated daily nicotine exposure that are consistent with effects seen after prolonged abstinence from cocaine. Thus, these changes in glutamate receptor function and transmission may be enduring and may contribute to relapse independent of when the relapse occurs, shortly after the last drug consumption at the time when drug consumption would have resumed, or after a prolonged period of abstinence. This hypothesis is consistent with the finding that LY379268 decreased both nicotine self-administration and cueinduced reinstatement of nicotine-seeking, both situations reflecting motivation to consume nicotine associated with activation of the glutamate system.

In summary, the present findings extend our understanding of the role of $\mathrm{mGlu} 2 / 3$ receptors in reward and motivational processes and suggest a role for $\mathrm{mGlu} 2 / 3$ receptors and enhanced glutamate neurotransmission, in particular in the NAc shell and the posterior VTA, in nicotine self-administration and cueinduced reinstatement of nicotine seeking. The lack of specificity of the effects on drug- and food-seeking behavior and the tolerance to the effects of chronic treatment with such compounds may restrict the use of $\mathrm{mGlu} 2 / 3$ receptor agonists as treatments for smoking cessation to certain situations only. Nevertheless, mGlu2/3 receptors represent promising targets for new therapeutics for nicotine dependence and warrant additional exploration in both the preclinical and clinical domains.

\section{References}

Adewale AS, Platt DM, Spealman RD (2006) Pharmacological stimulation of group II metabotropic glutamate receptors reduces cocaine selfadministration and cocaine-induced reinstatement of drug seeking in squirrel monkeys. J Pharmacol Exp Ther 318:922-931.

Backstrom P, Hyytia P (2005) Suppression of alcohol self-administration and cue-induced reinstatement of alcohol seeking by the $\mathrm{mGlu} 2 / 3$ receptor agonist LY379268 and the mGlu8 receptor agonist (S)-3,4-DCPG. Eur J Pharmacol 528:110-118.

Baker DA, McFarland K, Lake RW, Shen H, Tang XC, Toda S, Kalivas PW (2003) Neuroadaptations in cystine-glutamate exchange underlie cocaine relapse. Nat Neurosci 6:743-749.

Baptista MA, Martin-Fardon R, Weiss F (2004) Preferential effects of the metabotropic glutamate 2/3 receptor agonist LY379268 on conditioned reinstatement versus primary reinforcement: comparison between cocaine and a potent conventional reinforcer. J Neurosci 24:4723-4727.

Baptista MA, Martin-Fardon R, Weiss F (2005) Effects of LY379268, an mGlu2/3 agonist, on cocaine self-administration and cocaine primeinduced cocaine seeking behavior in cocaine-escalated versus nonescalated rats. Soc Neurosci Abstr 31:561.3.

Bell K, Duffy P, Kalivas PW (2000) Context-specific enhancement of glutamate transmission by cocaine. Neuropsychopharmacology 23:335-344.

Bespalov AY, Dravolina OA, Sukhanov I, Zakharova E, Blokhina E, Zvartau E, Danysz W, van Heeke G, Markou A (2005) Metabotropic glutamate receptor (mGluR5) antagonist MPEP attenuated cue- and scheduleinduced reinstatement of nicotine self-administration behavior in rats. Neuropharmacology 49 [Suppl 1]:167-178.

Bossert JM, Liu SY, Lu L, Shaham Y (2004) A role of ventral tegmental area glutamate in contextual cue-induced relapse to heroin seeking. J Neurosci 24:10726-10730.

Bossert JM, Busch RF, Gray SM (2005) The novel mGluR2/3 agonist LY379268 attenuates cue-induced reinstatement of heroin seeking. NeuroReport 16:1013-1016.

Bossert JM, Poles GC, Sheffler-Collins SI, Ghitza UE (2006a) The
mGluR2/3 agonist LY379268 attenuates context- and discrete cueinduced reinstatement of sucrose seeking but not sucrose selfadministration in rats. Behav Brain Res 173:148-152.

Bossert JM, Gray SM, Lu L, Shaham Y (2006b) Activation of group II metabotropic glutamate receptors in the nucleus accumbens attenuates context-induced relapse to heroin seeking. Neuropsychopharmacology 10:2197-2209.

Cabeza de Vaca S, Carr KD (1998) Food restriction enhances the central rewarding effect of abused drugs. J Neurosci 18:7502-7510.

Caggiula AR, Donny EC, Chaudhri N, Perkins KA, Evans-Martin FF, Sved AF (2002) Importance of nonpharmacological factors in nicotine selfadministration. Physiol Behav 77:683-687.

Campbell UC, Carroll ME (2001) Effects of ketoconazole on the acquisition of intravenous cocaine self-administration under different feeding conditions in rats. Psychopharmacology (Berl) 154:311-318.

Carlezon Jr WA, Wise RA (1996) Rewarding actions of phencyclidine and related drugs in nucleus accumbens shell and frontal cortex. J Neurosci 16:3112-3122.

Cartmell J, Schoepp DD (2000) Regulation of neurotransmitter release by metabotropic glutamate receptors. J Neurochem 75:889-907.

Cartmell J, Monn JA, Schoepp DD (1999) The metabotropic glutamate 2/3 receptor agonists LY354740 and LY379268 selectively attenuate phencyclidine versus $d$-amphetamine motor behaviors in rats. J Pharmacol Exp Ther 291:161-170.

Cartmell J, Monn JA, Schoepp DD (2000) The mGlu(2/3) receptor agonist LY379268 selectively blocks amphetamine ambulations and rearing. Eur J Pharmacol 400:221-224.

Conn PJ, Pin JP (1997) Pharmacology and functions of metabotropic glutamate receptors. Annu Rev Pharmacol Toxicol 37:205-237.

Cornish JL, Kalivas PW (2000) Glutamate transmission in the nucleus accumbens mediates relapse in cocaine addiction. J Neurosci 20:RC89(1-5).

Corrigall WA, Coen KM (1989) Nicotine maintains robust selfadministration in rats on a limited-access schedule. Psychopharmacology (Berl) 99:473-478.

Greenslade RG, Mitchell SN (2004) Selective action of (-)-2-oxa-4aminobicyclo[3.1.0] hexane-4,6-dicarboxylate (LY379268), a group II metabotropic glutamate receptor agonist, on basal and phencyclidineinduced dopamine release in the nucleus accumbens shell. Neuropharmacology 47:1-8.

Hotsenpiller G, Giorgetti M, Wolf ME (2001) Alterations in behaviour and glutamate transmission following presentation of stimuli previously associated with cocaine exposure. Eur J Neurosci 14:1843-1855.

Hu G, Duffy P, Swanson C, Ghasemzadeh MB, Kalivas PW (1999) The regulation of dopamine transmission by metabotropic glutamate receptors. J Pharmacol Exp Ther 289:412-416.

Ikemoto S, Qin M, Liu ZH (2006) Primary reinforcing effects of nicotine are triggered from multiple regions both inside and outside the ventral tegmental area. J Neurosci 26:723-730.

Kalivas PW (1993) Neurotransmitter regulation of dopamine neurons in the ventral tegmental area. Brain Res Brain Res Rev 18:75-113.

Kalivas PW (2004) Glutamate systems in cocaine addiction. Curr Opin Pharmacol 4:23-29.

Kalivas PW, Volkow ND (2005) The neural basis of addiction: a pathology of motivation and choice. Am J Psychiatry 162:1403-1413.

Karasawa J, Yoshimizu T, Chaki S (2006) A metabotropic glutamate 2/3 receptor antagonist, MGS0039, increases extracellular dopamine levels in the nucleus accumbens shell. Neurosci Lett 393:127-130.

Kenny PJ, Gasparini F, Markou A (2003) Group II metabotropic and alphaamino-3-hydroxy-5-methyl-4-isoxazole propionate (AMPA)/kainate glutamate receptors regulate the deficit in brain reward function associated with nicotine withdrawal in rats. J Pharmacol Exp Ther 306:1068-1076.

Kim JH, Austin JD, Tanabe L, Creekmore E, Vezina P (2005) Activation of group II mGlu receptors blocks the enhanced drug taking induced by previous exposure to amphetamine. Eur J Neurosci 21:295-300.

Lecca D, Cacciapaglia F, Valentini V, Gronli J, Spiga S, Di Chiara G (2006) Preferential increase of extracellular dopamine in the rat nucleus accumbens shell as compared to that in the core during acquisition and maintenance of intravenous nicotine self-administration. Psychopharmacology (Berl) 184:435-446.

Liechti ME, Markou A (2007) Interactive effects of the mGlu5 receptor antagonist MPEP and the mGlu2/3 receptor antagonist LY341495 on nico- 
tine self-administration and reward deficits associated with nicotine withdrawal in rats. Eur J Pharmacol 554:164-174.

Liu X, Caggiula AR, Yee SK, Nobuta H, Poland RE, Pechnick RN (2006) Reinstatement of nicotine-seeking behavior by drug-associated stimuli after extinction in rats. Psychopharmacology (Berl) 184:417-425.

Liu X, Caggiula AR, Yee SK, Nobuta H, Sved AF, Pechnick RN, Poland RE (2007) Mecamylamine attenuates cue-induced reinstatement of nicotine-seeking behavior in rats. Neuropsychopharmacology 32: $710-718$.

Mansvelder HD, McGehee DS (2000) Long-term potentiation of excitatory inputs to brain reward areas by nicotine. Neuron 27:349-357.

Markou A (2007) Metabotropic glutamate receptor antagonists: novel therapeutics for nicotine dependence and depression? Biol Psychiatry $61: 17-22$.

McFarland K, Lapish CC, Kalivas PW (2003) Prefrontal glutamate release into the core of the nucleus accumbens mediates cocaine-induced reinstatement of drug-seeking behavior. J Neurosci 23:3531-3537.

Monn JA, Valli MJ, Massey SM, Hansen MM, Kress TJ, Wepsiec JP, Harkness AR, Grutsch Jr JL, Wright RA, Johnson BG, Andis SL, Kingston A, Tomlinson R, Lewis R, Griffey KR, Tizzano JP, Schoepp DD (1999) Synthesis, pharmacological characterization, and molecular modeling of heterobicyclic amino acids related to (+)-2-aminobicyclo[3.1.0] hexane-2,6dicarboxylic acid (LY354740): identification of two new potent, selective, and systemically active agonists for group II metabotropic glutamate receptors. J Med Chem 42:1027-1040.

Moran MM, McFarland K, Melendez RI, Kalivas PW, Seamans JK (2005) Cystine/glutamate exchange regulates metabotropic glutamate receptor presynaptic inhibition of excitatory transmission and vulnerability to cocaine seeking. J Neurosci 25:6389-6393.

Neugebauer V, Zinebi F, Russell R, Gallagher JP, Shinnick-Gallagher P (2000) Cocaine and kindling alter the sensitivity of group II and III metabotropic glutamate receptors in the central amygdala. J Neurophysiol 84:759-770.

Ohishi H, Shigemoto R, Nakanishi S, Mizuno N (1993a) Distribution of the mRNA for a metabotropic glutamate receptor (mGluR3) in the rat brain: an in situ hybridization study. J Comp Neurol 335:252-266.

Ohishi H, Shigemoto R, Nakanishi S, Mizuno N (1993b) Distribution of the messenger RNA for a metabotropic glutamate receptor, mGluR2, in the central nervous system of the rat. Neuroscience 53:1009-1018.

Paterson NE, Froestl W, Markou A (2005) Repeated administration of the GABAB receptor agonist CGP44532 decreased nicotine selfadministration, and acute administration decreased cue-induced reinstatement of nicotine-seeking in rats. Neuropsychopharmacology 30:119-128.

Paxinos G, Watson C (1998) The rat brain in stereotaxic coordinates, Ed 4. San Diego: Academic.

Peters J, Kalivas PW (2006) The group II metabotropic glutamate receptor agonist, LY379268, inhibits both cocaine- and food-seeking behavior in rats. Psychopharmacology (Berl) 186:143-149.
Picciotto MR, Corrigall WA (2002) Neuronal systems underlying behaviors related to nicotine addiction: neural circuits and molecular genetics. J Neurosci 22:3338-3341.

Pierce RC, Bell K, Duffy P, Kalivas PW (1996) Repeated cocaine augments excitatory amino acid transmission in the nucleus accumbens only in rats having developed behavioral sensitization. J Neurosci 16:1550-1560.

Richards G, Messer J, Malherbe P, Pink R, Brockhaus M, Stadler H, Wichmann J, Schaffhauser H, Mutel V (2005) Distribution and abundance of metabotropic glutamate receptor subtype 2 in rat brain revealed by $\left[{ }^{3} \mathrm{H}\right] \mathrm{LY} 354740$ binding in vitro and quantitative radioautography: correlation with the sites of synthesis, expression, and agonist stimulation of $\left[{ }^{35} \mathrm{~S}\right] \mathrm{GTP} \gamma \mathrm{S}$ binding. J Comp Neurol 487:15-27.

Rodd ZA, McKinzie DL, Bell RL, McQueen VK, Murphy JM, Schoepp DD, McBride WJ (2006) The metabotropic glutamate 2/3 receptor agonist LY404039 reduces alcohol-seeking but not alcohol self-administration in alcohol-preferring (P) rats. Behav Brain Res 171:207-215.

Rodd-Henricks ZA, McKinzie DL, Crile RS, Murphy JM, McBride WJ (2000) Regional heterogeneity for the intracranial self-administration of ethanol within the ventral tegmental area of female Wistar rats. Psychopharmacology (Berl) 149:217-224.

Schilstrom B, Fagerquist MV, Zhang X, Hertel P, Panagis G, Nomikos GG Svensson TH (2000) Putative role of presynaptic alpha7* nicotinic receptors in nicotine stimulated increases of extracellular levels of glutamate and aspartate in the ventral tegmental area. Synapse 38:375-383.

Schoepp DD, Jane DE, Monn JA (1999) Pharmacological agents acting at subtypes of metabotropic glutamate receptors. Neuropharmacology 38:1431-1476.

Tamaru Y, Nomura S, Mizuno N, Shigemoto R (2001) Distribution of metabotropic glutamate receptor mGluR3 in the mouse CNS: differential location relative to pre- and postsynaptic sites. Neuroscience 106:481-503.

Wang F, Chen H, Steketee JD, Sharp BM (2007) Upregulation of ionotropic glutamate receptor subunits within specific mesocorticolimbic regions during chronic nicotine self-administration. Neuropsychopharmacology 32:103-109.

Xi ZX, Baker DA, Shen H, Carson DS, Kalivas PW (2002a) Group II metabotropic glutamate receptors modulate extracellular glutamate in the nucleus accumbens. J Pharmacol Exp Ther 300:162-171.

Xi ZX, Ramamoorthy S, Baker DA, Shen H, Samuvel DJ, Kalivas PW (2002b) Modulation of group II metabotropic glutamate receptor signaling by chronic cocaine. J Pharmacol Exp Ther 303:608-615.

Zangen A, Ikemoto S, Zadina JE, Wise RA (2002) Rewarding and psychomotor stimulant effects of endomorphin-1: anteroposterior differences within the ventral tegmental area and lack of effect in nucleus accumbens. J Neurosci 22:7225-7233.

Zhao Y, Dayas CV, Aujla H, Baptista MA, Martin-Fardon R, Weiss F (2006) Activation of group II metabotropic glutamate receptors attenuates both stress and cue-induced ethanol-seeking and modulates c-fos expression in the hippocampus and amygdala. J Neurosci 26:9967-9974. 